\title{
Rapid shifts in the thermal sensitivity of growth but not development rate causes temperature-size response variability during ontogeny in arthropods
}

\author{
Horne, Curtis R.; Hirst, Andrew G.; Atkinson, David; Almeda, Rodrigo; Kiørboe, Thomas
}

Published in:

Oikos

Link to article, DOI:

10.1111/oik.06016

Publication date:

2019

Document Version

Version created as part of publication process; publisher's layout; not normally made publicly available

Link back to DTU Orbit

Citation (APA):

Horne, C. R., Hirst, A. G., Atkinson, D., Almeda, R., \& Kiørboe, T. (2019). Rapid shifts in the thermal sensitivity of growth but not development rate causes temperature-size response variability during ontogeny in arthropods. Oikos, 128(6), 823-835. https://doi.org/10.1111/oik.06016

\section{General rights}

Copyright and moral rights for the publications made accessible in the public portal are retained by the authors and/or other copyright owners and it is a condition of accessing publications that users recognise and abide by the legal requirements associated with these rights.

- Users may download and print one copy of any publication from the public portal for the purpose of private study or research.

- You may not further distribute the material or use it for any profit-making activity or commercial gain

- You may freely distribute the URL identifying the publication in the public portal 


\section{Rapid shifts in the thermal sensitivity of growth but not development rate causes temperature-size response variability during ontogeny in arthropods}

Curtis R. Horne ${ }^{1}$, Andrew. G. Hirst ${ }^{1,2}$, David Atkinson ${ }^{3}$, Rodrigo Almeda ${ }^{2}$ and Thomas Kiørboe $^{2}$

${ }^{1}$ School of Environmental Sciences, Univ. of Liverpool, Liverpool, L69 3GP, UK

${ }^{2}$ Centre for Ocean Life, DTU Aqua, Technical Univ. of Denmark, Lyngby, Denmark

${ }^{3}$ Inst. of Integrative Biology, Univ. of Liverpool, Liverpool, UK

Corresponding author: Curtis R. Horne, School of Environmental Sciences, Univ. of Liverpool, Liverpool, L69 3GP, UK. E-mail: c.r.horne@liverpool.ac.uk

Decision date: $31-$ Dec-2018

This article has been accepted for publication and undergone full peer review but has not been through the copyediting, typesetting, pagination and proofreading process, which may lead to differences between this version and the Version of Record. Please cite this article as doi: [10.1111/oik.06016]. 


\begin{abstract}
Size at maturity in ectotherms commonly declines with warming. This near-universal phenomenon, formalised as the temperature-size rule, has been observed in over $80 \%$ of tested species, from bacteria to fish. The proximate cause has been attributed to the greater temperature dependence of development rate than growth rate, causing individuals to develop earlier but mature smaller in the warm. However, few studies have examined the ontogenetic progression of the temperature-size response at high resolution. Using marine planktonic copepods, we experimentally determined the progression of the temperature-size response over ontogeny. Temperature-size responses were not generated gradually from egg to adult, contrary to the predictions of a naïve model in which development rate was assumed to be more temperature-dependent than growth rate, and the difference in the temperature dependence of these two rates remained constant over ontogeny. Instead, the ontogenetic progression of the temperature-size response in experimental animals was highly episodic, indicating rapid changes in the extent to which growth and development rates are thermally decoupled. The strongest temperature-size responses occurred temporally mid-way through ontogeny, corresponding with the point at which individuals reached between $\sim 5-25 \%$ of their adult mass. Using the copepod Oithona nana, we show that the temperature-dependence of growth rate varied substantially throughout ontogeny, whereas the temperature dependence of development rate remained constant. The temperature-dependence of growth rate even exceeded that of development rate in some life stages, leading to a weakening of the temperature-size response. Our analyses of arthropod temperature-size responses from the literature, including crustaceans and insects, support these conclusions more broadly. Overall, our findings provide a better understanding of how the temperature-size rule is produced over ontogeny. Whereas we find support for the generality of developmental rate isomorphy in arthropods (shared temperature dependence of development rate across life stages), this concept should not apply to growth rates.
\end{abstract}

Keywords: body size, plasticity, warming 


\section{INTRODUCTION}

Body size is directly linked to organism fitness. Metabolism, reproduction, and survival, as well as the structure of food webs, predator-prey interactions, and population productivity can all be influenced by body size (Kleiber, 1947; Peters, 1983; Brown et al., 2004; Hirst et al., 2014; Sentis et al., 2017). Consequently, shifts in the size of animals and size-spectra of biological communities, such as those arising from environmental warming, are likely to have ecological and economic impacts (e.g. Vanni, 1987; Greenleaf et al., 2007; Sheridan \& Bickford, 2011; Osmond et al., 2017). For these reasons, understanding what drives body size variation is of fundamental biological importance.

In ectotherms, species frequently grow to a smaller size-at-stage with increasing temperature under controlled laboratory conditions (Atkinson, 1994). This intra-specific, phenotypically plastic response, formalised as the temperature-size rule, has been observed in a diverse range of taxa including protists, rotifers, arthropods, cnidarians, tunicates, chaetognaths, fish, amphibians and plants (Atkinson, 1994; Forster et al., 2012; Horne et al., 2015). Systematic differences in the magnitude and direction of adult temperature-size responses have been identified between taxa and environments, suggesting that the selective pressures driving body size change with warming differ between groups with different life histories (Forster et al., 2012; Horne et al., 2015; Horne et al., 2016; Horne et al., 2017). Similarly, temperature-size responses can also vary between different life stages within a species, but relatively few studies have examined temperature-size responses over ontogeny at such high resolution (although see Gulbrandsen \& Johnsen, 1990; Leandro et al., 2006a; Forster et al., 2011a).

Examining temperature-size responses over ontogeny is valuable because it can provide important insight into the processes underlying ontogenetic growth and development. Body size-at-stage is ultimately dependent upon growth and development rates, as well as the initial progeny size. The proximate mechanisms by which temperature-size responses are achieved can be attributed to differences in the temperature dependence of both growth and development rates (van der Have \& de Jong, 1996; Forster et al., 2011a; Forster et al., 2011b; Forster et al., 2013). For metazoans, one proposed mechanism lies in DNA replication having a greater sensitivity to temperature (associated with differentiation and therefore development) than protein synthesis (associated with growth). Specifically, diffusion, the speed of which is relatively insensitive to temperature, may be less rate-limiting in DNA replication than in protein synthesis (van der Have \& de Jong, 1996). This mechanism has been proposed to underlie the greater temperature dependence of differentiation than growth rate. As temperature increases, development rate 
increases faster than growth rate, causing individuals to develop earlier but mature smaller (Forster et al., 2011a; Forster et al., 2011b).

In the few studies that have examined temperature-size responses over ontogeny, most report highly nonlinear patterns or episodic shifts in the progression of the temperature-size response over the course of development. Progeny size often shows comparatively little or no response to rearing temperature relative to the greater size response of adults, but the strength of the temperature-size response can both increase and decrease between distinct life stages (Gulbrandsen \& Johnsen, 1990; Leandro et al., 2006a; Forster et al., 2011a). The irregular progression of the temperature-size response suggests that the extent to which growth and development rates are thermally decoupled may vary over ontogeny, which challenges conventional assumptions regarding rate isomorphy. In arthropods for example, including insects and crustaceans, many species are assumed to have developmental rate isomorphy (commonly referred to as 'equiproportional development' in zooplankton). This describes how the temperature dependence of development rate is shared across distinct ontogenetic stages (Hart, 1990; Jarošík et al., 2004). A similar concept can also be hypothesized for growth rate, i.e. an assumption that mass-specific growth rate of any particular juvenile stage has the same temperature dependence as all other juvenile stages. Variation in the temperature-size response over ontogeny challenges one or both of these assumptions, but whether this variation generally arises from changes in the temperature dependence of growth rate, development rate, or a combination of both, is unknown.

Here we examine the progression of the temperature-size response over ontogeny in copepods, to determine how the temperature dependence of growth and development rate varies between life stages. Copepods globally represent a primary food resource for invertebrate and vertebrate predators, including fish, and are one of the most abundant metazoans on the planet (Humes, 1994; Ware \& Thomson, 2005). In general, the postembryonic development of planktonic copepods is characterized by six naupliar stages (N1-N6), five copepodite stages (C1-C5), and the adult stage (C6), all of which can be distinguished based on external morphological features. This makes copepods an excellent model organism in which to investigate patterns in the temperature-size response over ontogeny. In particular, we aim to determine whether:

i. the degree to which growth and development rates are thermally decoupled is constant, or rather varies during ontogeny.

'This article is protected by copyright. All rights reserved.' 
ii. the episodic progression of the temperature-size response results from variation in the temperature dependence of growth rate, development rate, or a combination of both.

iii. the pattern of change in the thermal sensitivities of growth and development rate during ontogeny is comparable, or dissimilar, among species.

To address these objectives, we construct a naïve model to predict the progression of the temperature-size response over ontogeny, using a wide range of realistic values of copepod growth rate, development rate, and their temperature dependence. When making these predictions, we assume that development rate is more temperature-dependent than growth rate (van der Have \& de Jong, 1996; Forster et al., 2011b), and the temperature dependence of each of these two rates does not vary among life stages (i.e. that both growth and development exhibit rate isomorphy). Next, we experimentally determine the stage-to-stage progression of the temperature-size response over the course of a single generation in several planktonic copepod species, comparing patterns from our empirical data with those predicted by the model. We then quantify stage-specific development and growth rates, to determine their temperature dependence. Finally, we analyse data from the literature for other arthropod species, including crustaceans and insects, to test the generality of our results within this phyla.

\section{MATERIALS AND METHODS}

Modelling the Progression of the Temperature-Size Response Over Ontogeny

We constructed a naïve model to predict stage-specific variation in body mass with temperature over ontogeny in planktonic copepods, using a wide range of realistic values of copepod development rate, growth rate, and their temperature dependence (outlined below and summarised in Table S1 of our Supporting Information). This allowed us to model the progression of the temperature-size response across life stages and through time.

To begin, development time between life stages was initially assumed to be isochronal (i.e. each juvenile stage having the same time duration), whilst also having a constant degree of temperature dependence that did not change over ontogeny - an implicit assumption of the equiproportional development concept in zooplankton (Hart, 1990). We estimated development time at different temperatures using a Bělehrádek function, defined as:

$$
D_{t}=675(T+2.7)^{-2.05}
$$

'This article is protected by copyright. All rights reserved.' 
where $D_{t}$ is the stage-specific median development time (days) and $T$ is the temperature $\left({ }^{\circ} \mathrm{C}\right)$. We chose to fix the shape of the response using a scaling exponent of 2.05 , which is assumed to be relatively conserved among different species within a copepod taxon (McLaren, 1995). The remaining parameter values were chosen to ensure that our estimations of $D_{t}$ corresponded with realistic development times reported in the literature (e.g. Leandro et al., 2006a; Almeda et al., 2010).

Many copepods have near exponential growth over much of ontogeny under non-limiting food conditions (e.g. Acartia, Oithona and many other genera) (Miller et al., 1977; Almeda et al., 2010), and thus mass was assumed to increase exponentially over time, i.e., have a constant mass-specific growth rate throughout ontogeny. Based on realistic values reported in Kiørboe and Sabatini (1995), mass-specific growth rate was initially set at $0.2 \mathrm{~d}^{-1}$ at $15^{\circ} \mathrm{C}$. These initial values were used to calculate mass-specific growth rate at a range of different temperatures, assuming a fixed $\mathrm{Q}_{10}$ temperature coefficient of 2.5 (i.e. for every $10^{\circ} \mathrm{C}$ increase in temperature, growth rate increased 2.5 -fold), chosen based on realistic $\mathrm{Q}_{10}$ values reported in Hirst and Bunker (2003). Specifically:

$G R_{T 2}=G R_{T 1} \times Q_{10}{ }^{(T 2-T 1) / 10}$

where $G R_{\mathrm{T} 1}$ is the initial mass-specific growth rate at temperature $T 1$ (i.e. $0.2 \mathrm{~d}^{-1}$ at $15^{\circ} \mathrm{C}$ ), $Q_{10}=2.5$, and $G R_{T 2}$ is the mass-specific growth rate at temperature $T 2$ (calculated for temperatures between 0 and $\left.30^{\circ} \mathrm{C}\right)$.

We combined our estimates of development time and growth rate to determine stage-specific body mass $\left(M_{i+1}\right)$ at different temperatures, ranging from 0 to $30^{\circ} \mathrm{C}$, defined as:

$M_{i+1}=M_{i} \times \exp ^{\left(G R \times D_{t}\right)}$

where $M_{i}$ is the mass of the previous life stage (egg mass in the first instance), and GR and $D_{t}$ are the mass-specific growth rates and median development times between stage $i$ and $i+1$ at a given temperature. We assigned egg mass a value representative of small neritic copepod species $(0.043 \mu \mathrm{g}$ dry mass), and assumed egg mass to have no temperature-size response (Forster et al., 2011a).

'This article is protected by copyright. All rights reserved.' 
Using these estimates, we determined the slopes of ordinary least-squares (OLS) regressions of $\ln$ transformed body mass vs. temperature for each life stage. This exponential (log-linear) equation form has consistently been found to be the best for modelling temperature-size responses (Forster et al., 2012; Horne et al., 2015; Horne et al., 2017). These stage-specific slopes were transformed into percentage change in mass per degree Celsius, using the formula $\left(\exp ^{(\text {slope) }}-1\right) * 100=\%$ change in mass per ${ }^{\circ} \mathrm{C}$ (Forster et al., 2012). Lastly, we converted these stage-specific temperature-size responses to a proportion of the final adult response, allowing us to model the progression of the temperature-size responses across life stages and through time (Figure 1).

Whereas mass often increases exponentially over time under non-limiting food conditions in many copepods (Miller et al., 1977; Almeda et al., 2010), some copepods grow slower in later life stages (Hirst \& Bunker, 2003). Some copepods also commonly have longer development times in later copepodite stages (Landry, 1983). We therefore generated a range of realistic alternative model outputs, to explore how variation in growth and development rates over ontogeny might impact the progression of the temperature-size response (the range of predictions from these alternative model outputs are encompassed by the shaded area in Figure 1). These alternative trajectories allowed for both non-exponential growth (up to a $10 \%$ decline in growth rate per stage over ontogeny) and increases in stage duration (up to a $25 \%$ increase in stage duration per stage). We also varied the initial growth rate set at $15^{\circ} \mathrm{C}$, ranging between 0.1 to $0.4 \mathrm{~d}^{-1}$ (based on values reported in Kiørboe and Sabatini (1995)), as well as its temperature dependence, with $\mathrm{Q}_{10}$ values ranging from 1.5 to 4 (based on values reported in Hirst and Bunker (2003)). Importantly, in all our models the temperature dependence of both growth and development rate was kept constant over ontogeny. These predictions were then compared with empirical temperature-size data for planktonic copepods. Note that body size decreased with warming in all our model trajectories; hence, development rate always increased faster than growth rate with temperature, resulting in earlier development at a smaller size in the warm. Consequently, whilst the temperature dependence of the Bělehrádek function used to model development rate (i.e. equation 1) cannot be equated to a standard $\mathrm{Q}_{10}$ temperature coefficient, our predictions always followed the assumption that development rate is on average more temperature-dependent than growth rate (van der Have \& de Jong, 1996; Forster et al., 2011b). A summary of all the model components and range of parameter values is presented in Table S1 of our Supporting Information.

'This article is protected by copyright. All rights reserved.' 


\section{Experimentation and Data Collection}

Three calanoid copepod species (Acartia tonsa, Centropages hamatus, and Temora longicornis) and one cyclopoid species (Oithona nana), were reared from egg or nauplii stage 1 to maturity under saturating food conditions at three constant temperature treatments $\left(10,15,20^{\circ} \mathrm{C}\right)$. All four species were reared separately throughout the experiment using two replicates per temperature, resulting in 24 experimental cultures.

Copepods were obtained from continuous laboratory cultures at Danish Technical University DTUAQUA. Stock cultures were maintained at $\sim 16^{\circ} \mathrm{C}$. Specimens of A. tonsa, C. hamatus and T. longicornis were originally isolated from the Skagerrak strait (North Sea, Sweden) and Øresund strait (North Sea, Denmark). O. nana were obtained from the Port of Gijon (Cantabrian Sea, Spain). All four species are widely distributed, but particularly common in temperate coastal regions (Razouls et al., 2005-2018). Annual temperature variability is typically $>10^{\circ} \mathrm{C}$ in these regions (Horne et al., 2017). Thus, temperature treatments were chosen to reflect considerable but realistic seasonal variation in temperature, thereby also increasing the likelihood of detecting significant changes in body size with warming.

Given that the temperature-size response is a phenotypically plastic response, we chose not to acclimate organisms to the test temperatures before the start of the experiment, but rather to measure the response within a single generation. Eggs of $C$. hamatus (starting density of $\sim 700$ eggs $\mathrm{L}^{-1}$ ) and T. longicornis (starting density $\sim 150$ eggs $\mathrm{L}^{-1}$ ), and stage 1 nauplii $(\mathrm{N} 1)$ of $O$. nana (starting density $\sim 1875$ individuals $\mathrm{L}^{-1}$ ) were harvested directly from stock cultures and immediately transferred to each temperature treatment. $O$. nana cultures were established using nauplii instead of eggs, because in this species females carry the eggs until hatching. A. tonsa cultures were seeded with eggs held for long periods at $4^{\circ} \mathrm{C}$, at which temperature they do not hatch (starting density $\sim 5300$ eggs $\mathrm{L}^{-1}$, assuming $25 \%$ hatch success (Drillet et al., 2011)).

All experimental cultures were reared in open-top 2L Duran bottles containing filtered seawater (salinity $32 \mathrm{psu})$. Cultures were incubated at each constant temperature treatment by placing the bottles into highdensity polyethylene water baths, each connected via a water pump to a closed loop temperature control system equipped with a digital thermostat (TECO TK2000 aquarium chiller; $\pm 0.5^{\circ} \mathrm{C}$ ). Insulating foam was placed around the connecting tubing to reduce heat transfer. Cultures were permanently aerated by bubbling a constant low flow of atmospheric air directly into each bottle. All species were fed the 
dinoflagellate Oxyrrhis marina obtained from stock cultures kept at $16^{\circ} \mathrm{C}$. Food levels in the copepod cultures were maintained at $\geq 3000$ cells ml$^{-1}\left(\geq 1500\right.$ cells $\mathrm{ml}^{-1}$ for the much smaller $O$. nana, ) to ensure saturated food conditions (Leandro et al., 2006a; Saage et al., 2009; Almeda et al., 2010; Gonçalves et al., 2014). Food concentrations were measured either daily, or every $48 \mathrm{~h}$ at $10^{\circ} \mathrm{C}$, using a Beckman

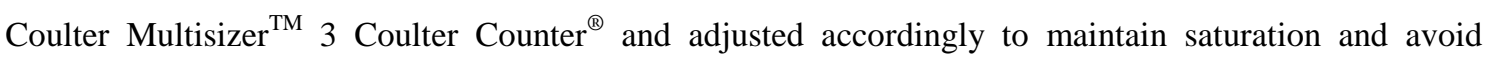
possible confounding effects of food limitation.

To measure body size of the different developmental stages throughout ontogeny, an $80 \mathrm{~mL}$ sample was collected from each culture every $24 \mathrm{~h}$ and filtered through a $40-\mu \mathrm{m}$ mesh. The collected individuals were then preserved in $0.5 \%$ Lugol's solution for staging and sizing. Due to the much lower stocking density of T. longicornis in our experimental cultures, samples of this species were collected and preserved from only three time points (nauplii stage 6, copepodite stage 1 and the adult stage), determined by regularly staging and then returning a sub-sample of individuals from each culture. On average, total development time (egg to adult) ranged from 17 days at $20^{\circ} \mathrm{C}$ to 45 days at $10^{\circ} \mathrm{C}$. All species were successfully reared to maturity at each temperature treatment, except for $O$. nana, which did not reach maturity at $10^{\circ} \mathrm{C}$ within our experimental period. Thus, O. nana individuals reared at $10^{\circ} \mathrm{C}$ were excluded from our analyses.

All preserved individuals were staged under an inverted microscope using taxonomic guides (e.g. Conway, 2006). To determine body size, digital pictures of $\sim 30$ random individuals from each temperature treatment and developmental stage (separated by sex in later copepodite stages) were taken with a camera attached to an inverted microscope. Total body length without spines $(\mu \mathrm{m})$ for nauplii, and prosome length $(\mu \mathrm{m})$ for copepodites (anterior margin of the head to between the first and second segments of the slender posterior portion in the cyclopoid $O$. nana) were measured using image analysis software (Volocity ${ }^{\circledR}$ v.5.3.1, PerkinElmer) and subsequently converted to dry mass using previously published nauplii- and copepodite-specific length-mass regressions for each species (see Data Set S1 in Supporting Information for the raw body size data, length-mass regressions and their sources). A total of 5,620 body size measurements were recorded across all four copepod species, developmental stages and treatments. Arithmetic mean body masses for each species at each life stage and rearing temperature are available in Table S2 of our Supporting Information.

'This article is protected by copyright. All rights reserved.' 
We also recorded the daily frequency distribution (based on the first 20 individuals per sample) of developmental stages in our $O$. nana cultures (due to time constraints, we were unable to collect this data for our other experimental species). This allowed us to obtain quantitative data on stage-specific development and growth rates, and to determine their temperature dependence. Stage-specific development times (days) were calculated as the median development times, i.e., from the point at which $50 \%$ of individuals reached stage $i$ to the point at which $50 \%$ of individuals reached stage $i+1$ (following Peterson \& Painting, 1990). We plotted the arcsine square root-transformed cumulative proportion of each stage against time, and used an OLS regression to estimate the point at which $50 \%$ of individuals had reached each stage (Peterson \& Painting, 1990) (see Figure S1 in Supporting Information). Although logit transformation of proportional data is usually favoured over arcsine square root transformation (Warton \& Hui, 2011), our data included proportional values of both 0 and 1, making the range of the logit scale problematic. Stage-specific development rate $\left(\right.$ day $\left.^{-1}\right)$ was calculated as the reciprocal of stage duration. We also obtained average stage durations at $15^{\circ} \mathrm{C}$ for A. tonsa, C. hamatus and T. longicornis from relevant literature sources (Breteler et al., 1982; Leandro et al., 2006a). This allowed us to estimate the progression of the temperature-size response over ontogeny as a proportion of the total development time (assuming equiproportional development (Hart, 1990).

Mass-specific growth rates from one stage to the next were calculated for $O$. nana by combining data on arithmetic mean masses of each stage, and development times across consecutive stages, following Hirst et al. (2005) (their equation 22). Importantly, this method accounts for the time interval between arithmetic mean mass at stage $i$ and $i+1$, which is a combination of the duration of stage $i$ and $i+1$. Note that, whereas our predictive model is defined in terms of individual mass, it is generally not possible to incubate and follow individual copepods over time, hence we followed a population in our experiments. The methodological issues and assumptions of the growth equations we applied to the population are explored in detail in Hirst et al. (2005).

\section{Statistical Analyses}

All statistical analyses were conducted in R (R Core Team, 2014). For each species, we first determined the OLS slopes of ln-transformed mass vs. temperature for each life stage (upper panels in Figure 2). These stage-specific OLS regressions were calculated using all the raw individual-level data (i.e. $n=30$ at each temperature and life stage), but for simplicity, we only show the mean body mass ( $\pm 95 \%$ CIs) at each temperature and life stage in Figure 2. These stage-specific slopes were transformed into percentage 
change in mass per degree Celsius, as described above. A negative percentage change indicates a decrease in body size with increasing temperature, following the temperature-size rule. Stage-specific temperaturesize responses $( \pm 95 \% \mathrm{CIs})$ were also converted to a proportion of the final adult response, allowing us to compare the progression of the temperature-size response to that predicted by our model.

The effect of temperature on $O$. nana growth and development rates was modelled using an exponential equation form (i.e. In-transformed rate vs. temperature), which is consistent with the exponential function used to estimate growth rate in our predictive model (equation 2). This ln-transformation also helped to ensure the data were normally distributed. Using either ln-transformed mass-specific growth rate or development rate as the response variable in a linear model, we modelled the effect of temperature, developmental stage and, importantly, their interaction, to determine whether the temperature dependence of growth rate or development rate varied significantly between life stages (two-way ANOVA using the anova function in R). Where there was a significant interaction, we used Tukey's HSD post-hoc test to determine which life stages differed significantly from one another in their temperature dependence of growth or development rate. For each life stage, we also calculated the ratio between the slopes of $\ln$ transformed mass-specific growth rate vs. temperature and ln-transformed development rate vs. temperature. This provided a measure of the extent to which growth and development rates were thermally decoupled in the life stage. We also used these stage-specific ratios to calculate a mean slope ratio across the whole of ontogeny.

To assess the generality of our results we evaluated whether growth and developmental rates showed a constant temperature dependence throughout ontogeny in other arthropod species, using data available in the published literature. Of the few studies that have examined the progression of the temperature-size response at such high resolution, Forster \& Hirst (2012) provided examples from the literature of temperature-size responses through ontogeny in several crustacean species. We therefore revisited these data and their original sources, and using the same methodology as described above, were able to test for ontogenetic changes in the temperature dependence of growth and development rates in five of these species (A. tonsa, Calanus finmarchicus, Calanus sinicus, Paracalanus sp. and Sinocalanus tenellus). We also searched published literature on the Web of Science database (http://apps.webofknowledge.com/) for examples that provided laboratory data on stage-specific size, growth and development rate responses to temperature over ontogeny in insects. The primary search term combinations used were: "insect" AND "body size" AND "temperature" AND ("growth" OR "development"). We consequently tested for 'This article is protected by copyright. All rights reserved.' 
ontogenetic changes in the temperature dependence of growth and development rate in four insect species (Aedes aegypti, Aphis fabae, Culex quinquefasciatus and Heliothis virescens). A list of these species and their data sources, as well as the outcomes from statistical tests, are provided in Table 1.

Data deposition

Data available from the Dryad Digital Repository: <http://dx.doi.org/10.5061/dryad.xxxxx> (Horne al. 2019).

\section{RESULTS}

Progression of the Temperature-Size Response Over Ontogeny

Early naupliar stages generally showed a weak or inverse temperature-size response, particularly in $A$. tonsa and $O$. nana, whereas later naupliar stages exhibited stronger reductions in body size with increasing temperature (Figure 2). In all species except for O. nana, the strongest temperature-size response did not occur in the transition to the adult stage, but rather in the transition from nauplii (N6) to copepodite (C1), which corresponds with a radical shift in body form. Subsequent copepodite stages tended to show a reduction in the strength of the temperature-size response into adulthood, although all species still adhered to the temperature-size rule as adults, maturing at a smaller size with increasing rearing temperature. Controlling for species as a random effect on the intercept in a linear mixed effects model (using package lmer in R), there was no significant interaction between temperature and sex acting on body size, suggesting that the strength of the temperature-size response did not differ between males and females (two-way ANOVA: $\mathrm{F}_{1,2065}=0.18, \mathrm{p}=0.67$; also see Figure 2).

Our empirical observations deviate considerably from the predictions of our naïve model, as inferred from no overlap of the $95 \%$ CIs with the range of model trajectories in Figure 3. These predictions were specifically based on the assumption that development rate is more temperature-dependent than growth rate, but that the temperature dependence of each of these two rates does not vary between life stages (i.e. rate isomorphy), resulting in the gradual onset of the temperature-size response from egg to adult. When this naïve model is compared against experimental data, the contrast highlights the inadequacies of the simple assumptions in the model. Specifically, the progression of the temperature-size response in our experimental species was episodic, both strengthening and weakening over the course of development, with the strongest temperature-size responses occurring mid-way through the ontogenetic time period (Figure 3a), on average corresponding with the point at which individuals reached between $\sim 5-25 \%$ of

'This article is protected by copyright. All rights reserved.' 
their adult mass (Figure 3b). In contrast to the model assumptions, this episodic progression of the temperature-size response suggests that the degree to which growth and development rates are thermally decoupled is not constant over ontogeny. Instead, growth rate, development rate, or both must differ in their temperature dependence between life stages in our experimental species.

\section{Temperature Dependence of Growth and Development Rates in O. nana}

On average across all life stages, the slope of ln-transformed mass-specific growth rate vs. temperature was weaker than that of development rate, such that the mean ratio between these two slopes was $<1$ (mean slope ratio $=0.81 \pm 0.43 ; 95 \% \mathrm{CI}$ ). However, this ratio varied substantially over ontogeny, caused by variation in the temperature dependence of growth rate, but not development rate, among life stages (Figure 4). Specifically, there was an interactive effect of temperature and life stage on ln-transformed mass-specific growth rate (two-way ANOVA: $\mathrm{F}_{7,16}=3.50, \mathrm{p}=0.02$ ), indicating that the temperature dependence of growth rate differed significantly between life stages. In contrast, we found no interactive effect of temperature and life stage on ln-transformed development rate (two-way ANOVA: $\mathrm{F}_{8,18}=0.19$, $\mathrm{p}=0.99$ ), indicating that the temperature dependence of development rate was rather conserved over ontogeny.

Patterns in the temperature-size response closely matched changes in slope ratio (Figure 4). For example, where the slope ratio was considerably less than 1 , the temperature dependence of growth rate was much weaker than that of development rate, and the temperature-size response strengthened between life stages, i.e. the temperature-size response became more negative (e.g. N5-N6 in Figure 4, slope ratio=0.14). Conversely, when the slope ratio was $>1$ this indicated that the slope of mass-specific growth rate vs. temperature was stronger than that of development rate, leading to a weakening of the temperature-size response between life stages, i.e. the temperature-size response became less negative (e.g. $\mathrm{C} 2-\mathrm{C} 3$ in Figure 4, slope ratio=1.58). These findings provide evidence that the highly irregular progression of the temperature-size response over ontogeny in $O$. nana, and hence variation in the extent to which growth and 
development rates are thermally decoupled, appears to be caused by variation in the temperature dependence of growth rate, as opposed to development rate.

\section{Further Examples from the Literature}

We also tested for ontogenetic changes in the temperature dependence of growth and development rates in other arthropod species from the literature. In addition to the examples presented in Forster and Hirst (2012), we also found evidence for similar episodic patterns in the progression of the temperature-size response in insects (Figure 5). The temperature dependence of growth rate varied significantly among life stages in eight of the nine species of zooplankton and insects analysed, whereas the temperature dependence of development rate varied significantly among life stages in only one species (Table 1). These findings suggest that variation in the temperature-size response over ontogeny in arthropods is generally caused by rapid changes in the temperature dependence of growth rate, rather than development rate.

\section{DISCUSSION}

Our work highlights how the temperature-size response observed in adults does not arise from the gradual onset of size responses over ontogeny, as predicted by our naïve model in which development rate is assumed to be more temperature-dependent than growth rate, and the temperature dependence of each of these two rates does not vary among life stages (Figure 1). Instead, the progression of the temperaturesize response over ontogeny is episodic and at times reverses (Figure 3), indicating that the extent to which growth and development rates are thermally decoupled can change rapidly from one life stage to the next.

It was possible to identify specific contributions of growth and development rates to observed temperature-size patterns in $O$. nana (Figure 4). Whereas the temperature dependence of development rate was consistent throughout the life cycle, the temperature dependence of growth rate varied considerably over ontogeny. Crucially, our analyses of ontogenetic temperature-size responses in other arthropod species from the literature, including both crustaceans and insects, largely support these conclusions (Table 1). These findings have important implications for understanding the mechanisms of the temperature-size rule, and provide evidence to suggest that, whereas developmental rate isomorphy 
(or equiproportional development) is often assumed for arthropods, this rule should not be assumed for growth.

\section{Explaining Variation in the Temperature-Dependence of Growth Rate}

It has been suggested that the temperature dependence of DNA replication (i.e. differentiation) is greater than the temperature dependence of protein synthesis (i.e. growth), resulting in earlier maturation at a smaller size in the warm (van der Have \& de Jong, 1996). Whilst on average we find that development rate is more temperature dependent than growth rate, the prediction is contradicted by the episodic progression of the temperature-size response over ontogeny, and importantly, by the sometimes greater temperature dependence of growth rate than development rate. Additionally, following the logic of Forster and Hirst (2012), the fact that many terrestrial univoltine insects show a positive temperature-size response (i.e. an increase in size with increasing temperature) (Horne et al., 2015), suggests that growth rate would be more temperature sensitive than development rate in these organisms (assuming the size of progeny is invariant with temperature). In any case, it is challenging: i) to explain why the thermal sensitivity of rates, particularly growth rate, varies over ontogeny, and ii) to determine whether this variation is systematic and therefore predictable. Despite observing similarities in the progression of the temperature-size response among our experimental species, the pattern itself is somewhat inconsistent.

One potential explanation for the observed variation in the temperature dependence of growth rate is that measurements of whole organism growth reflect different processes at the cellular level, encompassing not just individual cell growth but also cell differentiation. Given that the biological rates underlying these two processes may have a different temperature dependence (van der Have \& de Jong, 1996), variation in the temperature dependence of growth rate at the whole organism level may reflect changes in the prevalence of cell growth vs. cell differentiation over ontogeny. Copepods are generally considered to be eutelic (i.e., have a determinate number of somatic cells at maturity) (McLaren \& Marcogliese, 1983; Escribano et al., 1992), but the extent to which growth occurs by cell division (likely in earlier life stages), or by individual cell growth (likely in later life stages) may vary from one life stage to the next. For example, during earlier life stages one might predict that cell differentiation (assumed to be more sensitive to temperature than individual cell growth via protein synthesis) is likely to account for a relatively greater proportion of whole organism growth, particularly around the time of metamorphosis, which encompasses the differentiation of new cell types, tissues and organs (Gilbert, 2013). We find support for this hypothesis in our experimental species, in which most of the temperature-size response 
appears to be generated in earlier life stages approaching 'metamorphosis' (the transition from nauplii to copepodites), when individuals on average reached between 5 and $25 \%$ of their adult mass (Figure $3 \mathrm{~b}$ ).

Just as we observe variation in the magnitude of adult temperature-size responses between organisms with different life histories (e.g. aquatic vs. terrestrial, univoltine vs. multivoltine) (Forster et al., 2012; Horne et al., 2015; 2017), we should also consider that the selective pressures acting on body size may differ within species over ontogeny. Indeed, differences in the temperature dependence of growth rate among life stages, and consequently variation in the temperature-size response, suggests that a species' ability to cope with temperature change can vary over its life cycle. For instance, limiting factors other than temperature, such as resource availability, may constrain growth more strongly at certain life stages than others, thereby confounding the effects of temperature on growth rate, as well as other physiological rates and processes (Forster et al. 2011b; Boukal et al. 2015). These considerations are particularly pertinent in light of a recent review by Sinclair et al. (2016), who emphasise the importance of accounting for variation in thermal performance curves between life stages when predicting climate change impacts.

Another alternative explanation for the observed patterns is that the episodic progression of the temperature-size response arises from a mismatch between ontogenetic demands on energy (and thus scope for growth) in the laboratory versus those expected in nature. Should an organism find itself growing bigger in the laboratory than would be 'expected' given its evolutionary history in the field, for example because it is investing less in locomotion or 'defence', or because food quality and quantity are much greater than those encountered in typical field conditions, then feeding rates and size around the time of moult may be adjusted in subsequent life stages. However, this may be somewhat less significant here given that the experimental animals used in our study were obtained from well-established stock cultures maintained in the laboratory for a great many generations.

\section{Additional Implications and Observations}

Our findings support the proposal that developmental rate isomorphy is common among arthropods (Jarošík et al., 2002; Jarošík et al., 2004), whereas a similar concept should not be presumed for growth rate. We note that, due to assumptions hidden in the conventional methodology used to study development rate isomorphy, violation of this concept in insects and copepods may be more frequent than previously believed, as highlighted by Boukal et al. (2015). More specifically, conventional analyses often fail to account for the inherent proportional structure of the data, and/or tend to group larval instars 
together (Boukal et al., 2015). We were therefore interested to test the reliability of our own methodology, applying it to the raw data for Notonecta glauca reported in Boukal et al. (2015); a species in which their methodology detected variation in the temperature dependence of developmental rate, whereas standard analysis failed to do so. Reassuringly, when tested using the approach adopted herein, we also found that the temperature dependence of development rate was significantly dependent on life stage (two-way ANOVA: $\mathrm{F}_{4,190}=13.09, \mathrm{p}<0.001$ ). This gives us confidence in our approach, not just in assessing developmental rate isomorphy, but also in assessing ontogenetic variation in the temperature dependence of growth rate.

Patterns in adult temperature-size responses observed in our own study are also consistent with those previously reported in the literature. Our findings support the broader patterns in temperature-size responses observed in the laboratory, in which over $83 \%$ of ectotherms tested appear to adhere to the temperature-size rule (Atkinson, 1994). Similar patterns have also been observed in the field, where $90 \%$ of copepod species matured at a smaller size in warmer compared to colder seasons (Horne et al., 2016). In our study, T. longicornis, the largest species we cultured, exhibited the greatest adult temperature-size response $\left(-4.16 \%{ }^{\circ} \mathrm{C}^{-1}\right)$, followed by $C$. hamatus $\left(-2.41 \%{ }^{\circ} \mathrm{C}^{-1}\right)$ and $A$. tonsa $\left(-2.10 \%{ }^{\circ} \mathrm{C}^{-1}\right)$, whereas the weakest adult temperature-size response was observed in the cyclopoid $O$. nana $\left(-1.82 \%{ }^{\circ} \mathrm{C}^{-1}\right)$. This parallels the seasonal patterns described by Horne et al. (2016), in which current-feeding calanoids, particularly T. longicornis, exhibited the strongest seasonal reductions in body size with temperature, whereas ambush-feeding cyclopoids exhibited relatively weaker seasonal temperature-size responses. Finally, we observe similar temperature-size responses in males and females within a species, as is typically the case for Arthropoda, including copepods (Hirst et al., 2015).

\section{Conclusions}

To better understand the mechanisms producing temperature-size responses, we analysed the progression of the temperature-size response over the ontogeny of well-studied crustaceans and insects. Importantly, we demonstrate how adult temperature-size responses are not established progressively and cumulatively from egg to adult, and that ontogenetic variation in the temperature-size response in arthropods is most likely driven by variation in the temperature dependence of growth rate, rather than of development rate. Thus, whereas developmental rate isomorphy is often assumed for arthropods, our results indicate that this rule should not be assumed for growth. Furthermore, we find that the slope of mass-specific growth rate vs. temperature is at times steeper than that of development rate, leading us to question the general

'This article is protected by copyright. All rights reserved.' 
applicability of the van der Have and de Jong (1996) model, which suggests that the mechanistic basis of the temperature-size rule lies in the greater thermal sensitivity of DNA replication (associated with differentiation) than protein synthesis (associated with growth). Although this model seems to be supported on average across the whole of ontogeny, it does not appear to account for rapid shifts in the temperature dependence of growth and development rates between life stages, leading to variation in the extent to which these rates are thermally decoupled. Ultimately, if we are to understand how and why the temperature-size rule evolved, we require a greater awareness of the processes underlying the division and enlargement of cells, and how their numbers change in organisms during ontogeny. This includes how resources are partitioned and utilised over the course of development.

\section{DECLARATIONS}

\section{Acknowledgements}

We wish to thank Jack Melybe for his technical support and assistance in maintaining the algal cultures at DTU Aqua, and Hans van Someren Greve for his help with the experimental set up. Thank you also to Ryan Hackett-Brooks for assisting with sample collection. Finally, thank you to three anonymous reviewers' for their constructive feedback, which helped to greatly improve the work.

\section{Funding}

CRH was supported by a Natural Environment Research Council (NERC) Studentship NE/L501797/1. AGH was supported by NERC and the Department for Environment, Food and Rural Affairs [grant number NE/L003279/1, Marine Ecosystems Research Programme]. The Centre for Ocean Life is a VKR Centre of Excellence supported by the Villum Foundation.

\section{Author Contributions}

All authors designed the study and wrote the paper. CRH carried out the experimental work, collected the data and performed the statistical analyses.

\section{Conflicts of Interest}

No conflicts of interest declared.

'This article is protected by copyright. All rights reserved.' 


\section{REFERENCES}

Almeda, R., Calbet, A., Alcaraz, M., Yebra, L. \& Saiz, E. (2010) Effects of temperature and food concentration on the survival, development and growth rates of naupliar stages of Oithona davisae (Copepoda, Cyclopoida). Marine Ecology-Progress Series, 410: 97-109.

Atkinson, D. (1994) Temperature and organism size - A biological law for ectotherms? Advances in Ecological Research, 25: 1-58.

Boukal, D.S., Ditrich, T., Kutcherov, D., Sroka, P., Dudová, P. \& Papáček, M. (2015) Analyses of developmental rate isomorphy in ectotherms: Introducing the Dirichlet regression. PloS one, 10: e0129341.

Breteler, W., Fransz, H.G. \& Gonzalez, S.R. (1982) Growth and development of 4 calanoid copepod species under experimental and natural conditions. Netherlands Journal of Sea Research, 16: 195-207.

Brown, J.H., Gillooly, J.F., Allen, A.P., Savage, V.M. \& West, G.B. (2004) Toward a metabolic theory of ecology. Ecology, 85: 1771-1789.

Campbell, R.G., Wagner, M.M., Teegarden, G.J., Boudreau, C.A. \& Durbin, E.G. (2001) Growth and development rates of the copepod Calanus finmarchicus reared in the laboratory. Marine Ecology Progress Series, 221: 161-183.

Conway, D.V.P. (2006) Identification of the copepodite developmental stages of twenty-six North Atlantic copepods. Occasional Publications. Marine Biological Association of the United Kingdom, 21: 27.

Drillet, G., Hansen, B.W. \& Kiørboe, T. (2011) Resting egg production induced by food limitation in the calanoid copepod Acartia tonsa. Limnology and Oceanography, 56: 2064-2070.

Escribano, R., McLaren, I.A. \& Breteler, W.C.M.K. (1992) Innate and acquired variation of nuclear DNA contents of marine copepods. Genome, 35: 602-610.

Forster, J. \& Hirst, A.G. (2012) The temperature-size rule emerges from ontogenetic differences between growth and development rates. Functional Ecology, 26: 483-492.

Forster, J., Hirst, A.G. \& Atkinson, D. (2011a) How do organisms change size with changing temperature? The importance of reproductive method and ontogenetic timing. Functional Ecology, 25: 1024-1031.

Forster, J., Hirst, A.G. \& Woodward, G. (2011b) Growth and development rates have different thermal responses. American Naturalist, 178: 668-678.

'This article is protected by copyright. All rights reserved.' 
Forster, J., Hirst, A.G. \& Atkinson, D. (2012) Warming-induced reductions in body size are greater in aquatic than terrestrial species. Proceedings of the National Academy of Sciences, 109: 1931019314.

Forster, J., Hirst, A.G. \& Esteban, G.F. (2013) Achieving temperature-size changes in a unicellular organism. The ISME journal, 7: 28-36.

Gilbert, L. (2013) Metamorphosis: a problem in developmental biology. Springer Science \& Business Media.

Gonçalves, R.J., van Someren Gréve, H., Couespel, D. \& Kiørboe, T. (2014) Mechanisms of prey size selection in a suspension-feeding copepod, Temora longicornis. Marine Ecology-Progress Series, 517: 61-74.

Greenleaf, S.S., Williams, N.M., Winfree, R. \& Kremen, C. (2007) Bee foraging ranges and their relationship to body size. Oecologia, 153: 589-596.

Gulbrandsen, J. \& Johnsen, G.H. (1990) Temperature dependent development of parthenogenetic embryos in Daphnia pulex de Geer. Journal of Plankton Research, 12: 443-453.

Hart, R.C. (1990) Copepod postembryonic durations - pattern, conformity, and predictability - the realities of isochronal and equiproportional development, and trends in the copepodid-naupliar duration ratio. Hydrobiologia, 206: 175-206.

Hirst, A.G. \& Bunker, A.J. (2003) Growth of marine planktonic copepods: Global rates and patterns in relation to chlorophyll a, temperature, and body weight. Limnology and Oceanography, 48: 1988-2010.

Hirst, A.G., Peterson, W.T. \& Rothery, P. (2005) Errors in juvenile copepod growth rate estimates are widespread: problems with the Moult Rate method. Marine Ecology-Progress Series, 296: 263279.

Hirst, A.G., Glazier, D.S. \& Atkinson, D. (2014) Body shape shifting during growth permits tests that distinguish between competing geometric theories of metabolic scaling. Ecology Letters, 17: 1274-1281.

Hirst, A.G., Horne, C.R. \& Atkinson, D. (2015) Equal temperature-size responses of the sexes are widespread in arthropod species. Proceedings of the Royal Society of London B: Biological Sciences, 282: 20152475 .

Horne, C.R., Hirst, A.G. \& Atkinson, D. (2015) Temperature-size responses match latitudinal-size clines in arthropods, revealing critical differences between aquatic and terrestrial species. Ecology Letters, 18: 327-335.

'This article is protected by copyright. All rights reserved.' 
Horne, C.R., Hirst, A. \& Atkinson, D. (2017) Seasonal body size reductions with warming co-vary with major body size gradients in arthropod species. Proceedings of the Royal Society of London B: Biological Sciences, 284: 20170238.

Horne, C.R., Hirst, A.G., Atkinson, D., Neves, A. \& Kiørboe, T. (2016) A global synthesis of seasonal temperature-size responses in copepods. Global Ecology and Biogeography, 25: 988-999.

Horne, C. R. et al. 2019. Data from: Rapid shifts in the thermal sensitivity of growth but not development rate causes temperature-size response variability during ontogeny in arthropods. - Dryad Digital Repository, <http://dx.doi.org/10.5061/dryad.xxxxx>. Humes, A.G. (1994) How many copepods? Ecology and morphology of copepods, pp. 1-7. Springer. Jarošík, V., Honěk, A. \& Dixon, A.F.G. (2002) Developmental rate isomorphy in insects and mites. The American naturalist, 160: 497-510.

Jarošík, V., Kratochvil, L., Honěk, A. \& Dixon, A.F.G. (2004) A general rule for the dependence of developmental rate on temperature in ectothermic animals. Proceedings of the Royal Society of London B: Biological Sciences, 271: S219-S221.

Kimoto, K., Uye, S. \& Onbe, T. (1986) Growth characteristics of a brackish-water calanoid copepod Sinocalanus tenellus in relation to temperature and salinity. Bulletin of Plankton Society of Japan, 33: 43-57.

Kiørboe, T. \& Sabatini, M. (1995) Scaling of fecundity, growth and development in marine planktonic copepods. Marine Ecology-Progress Series, 120: 285-298.

Kleiber, M. (1947) Body size and metabolic rate. Physiological Reviews, 27: 511-541.

Landry, M.R. (1983) The development of marine calanoid copepods with comment on the isochronal rule. Limnology and Oceanography, 28: 614-624.

Leandro, S.M., Tiselius, P. \& Queiroga, H. (2006a) Growth and development of nauplii and copepodites of the estuarine copepod Acartia tonsa from southern Europe (Ria de Aveiro, Portugal) under saturating food conditions. Marine Biology, 150: 121-129.

Leandro, S.M., Queiroga, H., Rodriguez-Grana, L. \& Tiselius, P. (2006b) Temperature-dependent development and somatic growth in two allopatric populations of Acartia clausi (Copepoda : Calanoida). Marine Ecology-Progress Series, 322: 189-197.

Li, B. \& Mills, N. (2004) The influence of temperature on size as an indicator of host quality for the development of a solitary koinobiont parasitoid. Entomologia Experimentalis et Applicata, 110: 249-256.

'This article is protected by copyright. All rights reserved.' 
McLaren, I.A. (1995) Temperature-dependent development in marine copepods - comments on choices of models. Journal of Plankton Research, 17: 1385-1390.

McLaren, I.A. \& Marcogliese, D.J. (1983) Similar nucleus numbers among copepods. Canadian Journal of Zoology, 61: 721-724.

Miller, C.B., Johnson, J.K. \& Heinle, D.R. (1977) Growth rules in the marine copepod genus Acartia. Limnology and Oceanography, 22: 326-335.

Nadgauda, D. \& Pitre, H. (1983) Development, fecundity, and longevity of the tobacco budworm (Lepidoptera: Noctuidae) fed soybean, cotton, and artificial diet at three temperatures. Environmental Entomology, 12: 582-586.

Osmond, M.M., Barbour, M.A., Bernhardt, J.R., Pennell, M.W., Sunday, J.M., O'Connor, M.I., Kerkhoff, A.J. \& Bronstein, J.L. (2017) Warming-induced changes to body size stabilize consumerresource dynamics. The American Naturalist, 189

Peters, R.H. (1983) The ecological implications of body size. Cambridge University Press, Cambridge.

Peterson, W.T. \& Painting, S.J. (1990) Developmental rates of the copepods Calanus australis and Calanoides carinatus in the laboratory, with discussion of methods used for calculation of development time. Journal of Plankton Research, 12: 283-293.

R Core Team (2014) R: A language and environment for statistical computing. R Foundation for Statistical Computing, Vienna, Austria.

Razouls, C., De Bovée, F., Kouwenberg, J. \& Desreumaux, N. (2005-2018) Diversity and geographic distribution of marine planktonic copepods. Available from: http://copepodes.obs-banyuls.fr/en (accessed Sept. 2018).

Rueda, L., Patel, K., Axtell, R. \& Stinner, R. (1990) Temperature-dependent development and survival rates of Culex quinquefasciatus and Aedes aegypti (Diptera: Culicidae). Journal of Medical Entomology, 27: 892-898.

Saage, A., Vadstein, O. \& Sommer, U. (2009) Feeding behaviour of adult Centropages hamatus (Copepoda, Calanoida): functional response and selective feeding experiments. Journal of Sea Research, 62: 16-21.

Sentis, A., Binzer, A. \& Boukal, D.S. (2017) Temperature-size responses alter food chain persistence across environmental gradients. Ecology Letters, 20: 852-862.

Sheridan, J.A. \& Bickford, D. (2011) Shrinking body size as an ecological response to climate change. Nature Climate Change, 1: 401-406. 
Sinclair, B.J., Marshall, K.E., Sewell, M.A., Levesque, D.L., Willett, C.S., Slotsbo, S., Dong, Y., Harley, C.D.G., Marshall, D.J., Helmuth, B.S. \& Huey, R.B. (2016) Can we predict ectotherm responses to climate change using thermal performance curves and body temperatures? Ecology Letters, 19: $1372-1385$.

Uye, S. (1988) Temperature-dependent development and growth of Calanus sinicus (Copepoda, Calanoida) in the laboratory. Hydrobiologia, 167: 285-293.

Uye, S. (1991) Temperature-dependent development and growth of the planktonic copepod Paracalanus sp. In the laboratory. Bulletin of Plankton Society of Japan: 627-636.

van der Have, T.M. \& de Jong, G. (1996) Adult size in ectotherms: Temperature effects on growth and differentiation. Journal of Theoretical Biology, 183: 329-340.

Vanni, M.J. (1987) Effects of nutrients and zooplankton size on the structure of a phytoplankton community. Ecology, 68: 624-635.

Ware, D.M. \& Thomson, R.E. (2005) Bottom-up ecosystem trophic dynamics determine fish production in the Northeast Pacific. Science, 308: 1280-1284.

Warton, D.I. \& Hui, F.K. (2011) The arcsine is asinine: the analysis of proportions in ecology. Ecology, 92: $3-10$. 


\section{FIGURE LEGENDS}

Figure 1. Model predicting the progression of the temperature-size response (expressed as a proportion of the adult response) over ontogeny in copepods, both as a function of total development time (panel A) and of adult mass at $15^{\circ} \mathrm{C}$ (panel B). Predictions are based on a wide range of realistic values of copepod growth rate, development rate, and their temperature dependence. The initial model output (black circles) assumes isochronal development and exponential growth throughout ontogeny (growth rate $=0.2 \mathrm{day}^{-1}$ at $15^{\circ} \mathrm{C} ; \mathrm{Q}_{10}=2.5$ ). The shaded area encompasses a range of realistic alternative model outputs. These alternative trajectories allow for nonexponential growth (declining growth rate over ontogeny), increases in stage duration over ontogeny, and variation in the initial growth rate as well as its temperature dependence, with $Q_{10}$ values ranging from 1.5 to 4 (see Methods). Development rate was always assumed to have a greater temperature dependence than growth rate, with neither having a temperature dependence that varied over ontogeny. In all cases, the temperature-size response gradually strengthens over ontogeny, culminating with the strongest response in the adult stage. Note the reversed y-axes for ease of comparison with empirical data, as temperature-size responses are predicted to become more negative over ontogeny.

'This article is protected by copyright. All rights reserved.' 

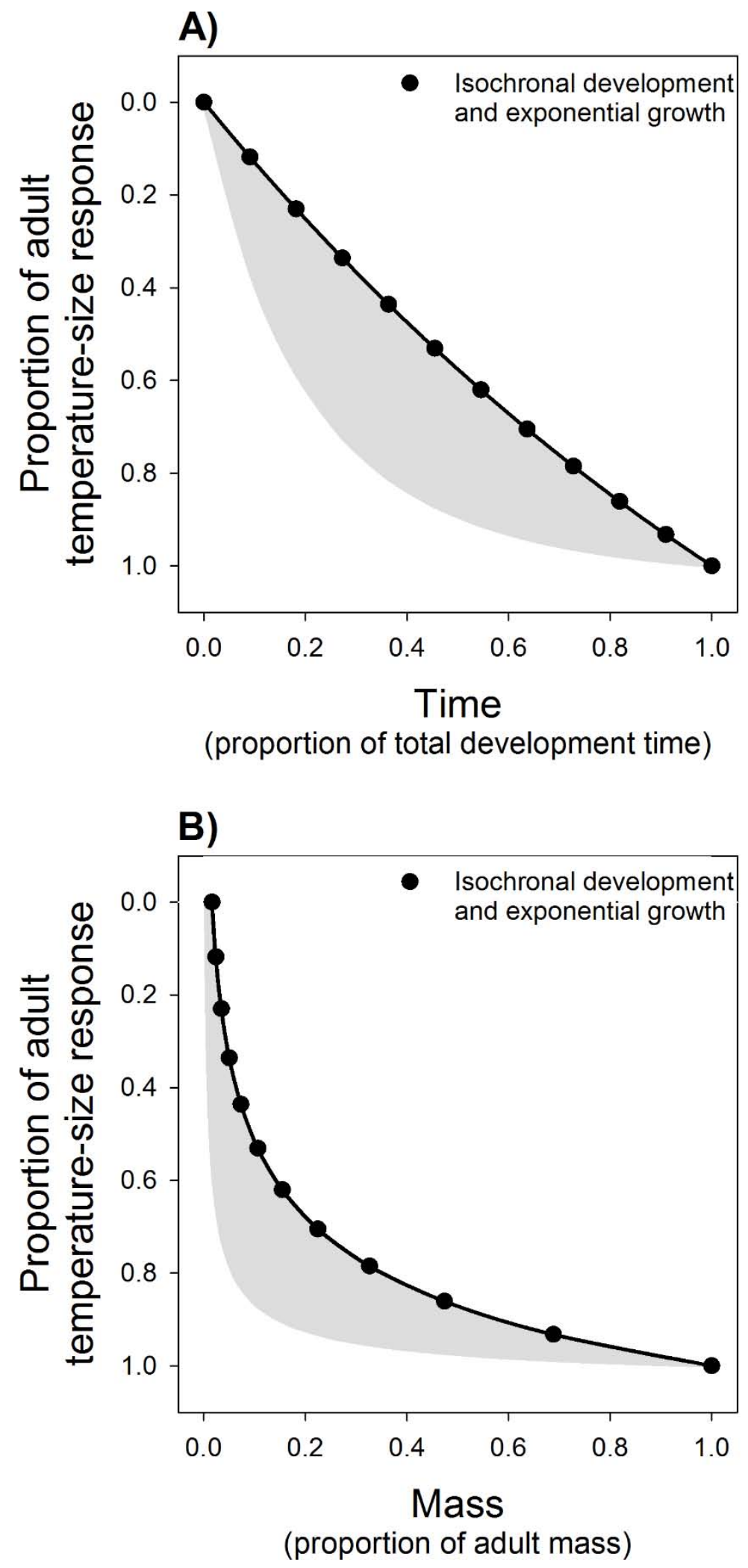

'This article is protected by copyright. All rights reserved.' 
Figure 2. Stage-specific OLS regressions of dry body mass $(\mu \mathrm{g})\left(\log _{10}\right.$ scale) vs. temperature for nauplii (N1N6; black symbols), copepodites and adults (C1-C5 and C6; open symbols), and associated temperature-size responses (percentage change in mass per ${ }^{\circ} \mathrm{C}$ ) for $A$. tonsa (panels $\mathrm{A}$ and B), C. hamatus (panels $\mathrm{C}$ and $\mathrm{D}$ ), $O$. nana (panels E and F; nauplii begin at stage N2) and T. longicornis (panels G and H; stages N6, C1 and C6 only). Note that stage-specific OLS regressions and temperature-size responses were generated using the raw individual-level data; however, for simplicity we plot mean body mass ( $\pm 95 \% \mathrm{CIs})$ at each temperature and stage for males and females combined (upper panels). Where body size measurements were separated by sex in later copepodite stages, temperature-size responses in the lower panels are depicted for males (grey symbols) and females separately.
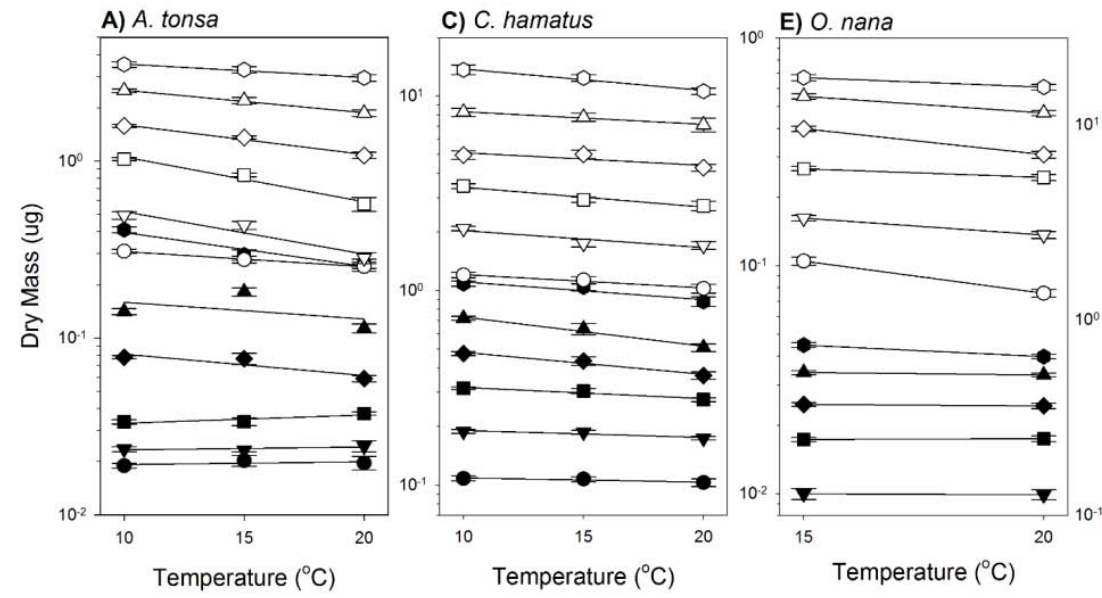

G) T. longicornis B) D)
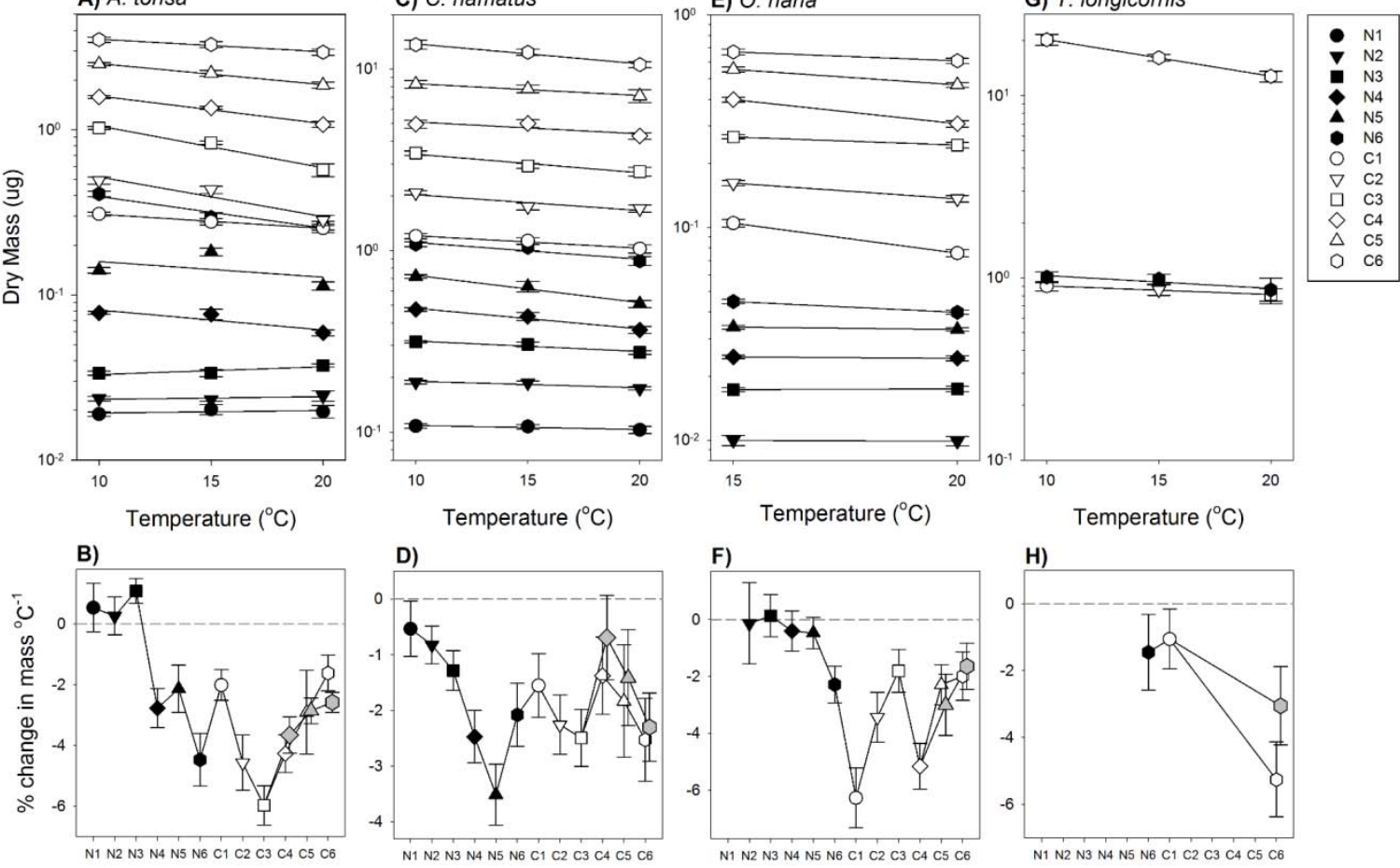

Life Stage

Life Stage

Life Stage

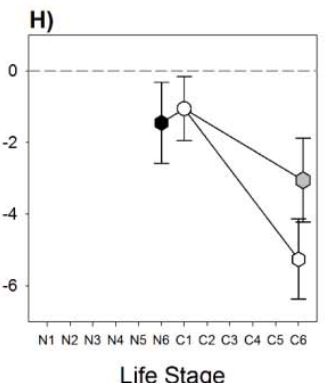

'This article is protected by copyright. All rights reserved.' 
Figure 3. The ontogenetic progression of the temperature-size response (expressed as a proportion of the adult response) vs. time (represented as a proportion of total development time at $15^{\circ} \mathrm{C}$ ) and mass (represented as a proportion of adult mass at $15^{\circ} \mathrm{C}$ ) for A. tonsa (panels A and B), C. hamatus (panels C and D) and O. nana (panels E and F). Data points $( \pm 95 \%$ CIs) represent different life stages. Note the reversal of the y-axes. The shaded area represents the range of realistic model predictions as defined in Figure 1.

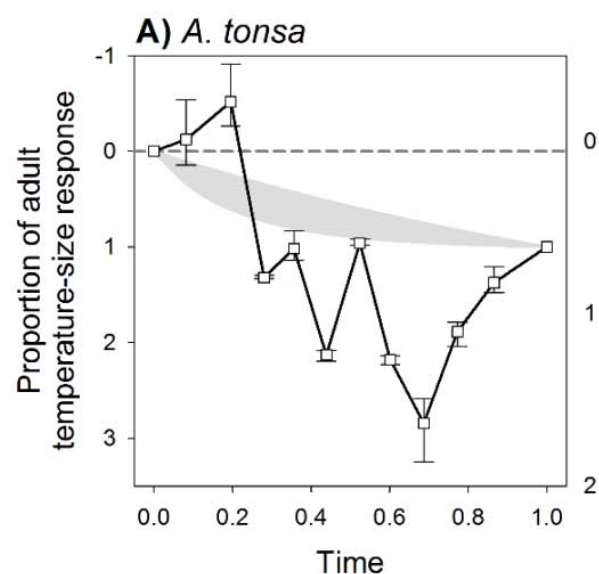

(proportion of total development time)

B)

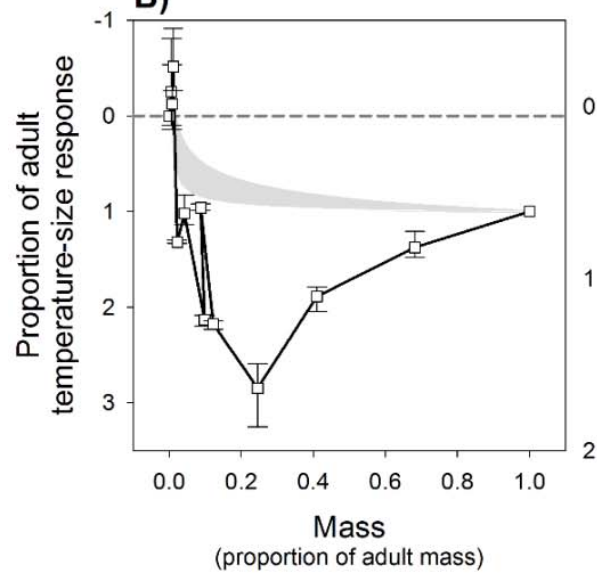

C) C. hamatus

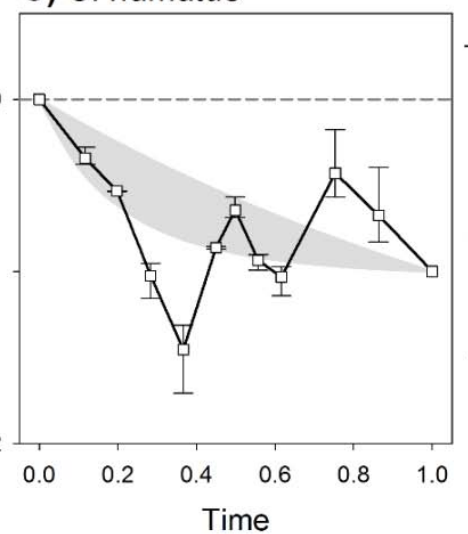

(proportion of total development time)

D)

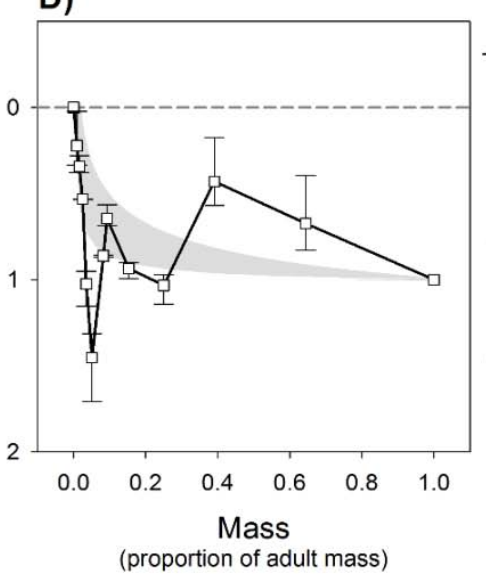

E) O. nana

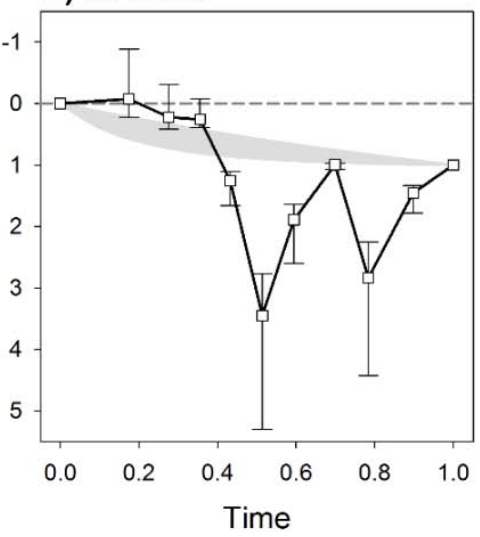

(proportion of total development time)

F)

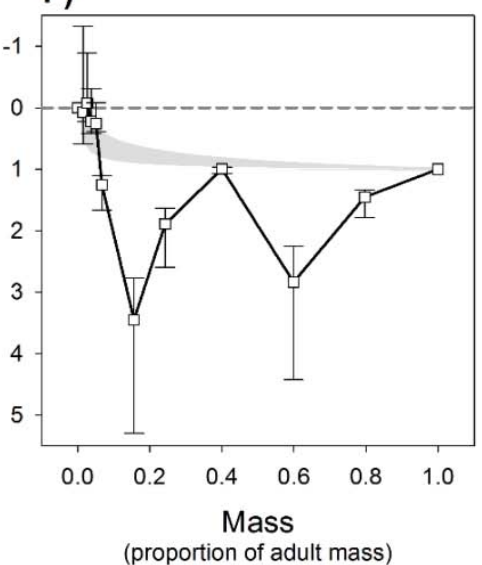

'This article is protected by copyright. All rights reserved.' 
Figure 4. A) Variation in the temperature dependence of mass-specific growth rate (black symbols and solid line) and development rate (open symbols and dashed line) between life stages in $O$. nana. Slope values were derived from stage-specific OLS regressions of $\ln$ transformed rate vs. temperature, where data from both experimental replicates were combined. Error bars denote standard error. B) Ontogenetic variation in the slope ratio (i.e. the ratio between the slopes of ln-transformed mass-specific growth rate vs. temperature and ln-transformed development rate vs. temperature; left-hand y-axis). Error bars denote standard error. Variation in the temperature-size response (encompassing 95\% CIs) is also shown for comparison, represented by the shaded area (right-hand y-axis). Whilst the slope of mass-specific growth rate vs. temperature is on average weaker than that of development rate, the ratio of these slopes varies substantially over ontogeny, caused by significant variation in the temperature dependence of growth rate, but not development rate, between life stages.
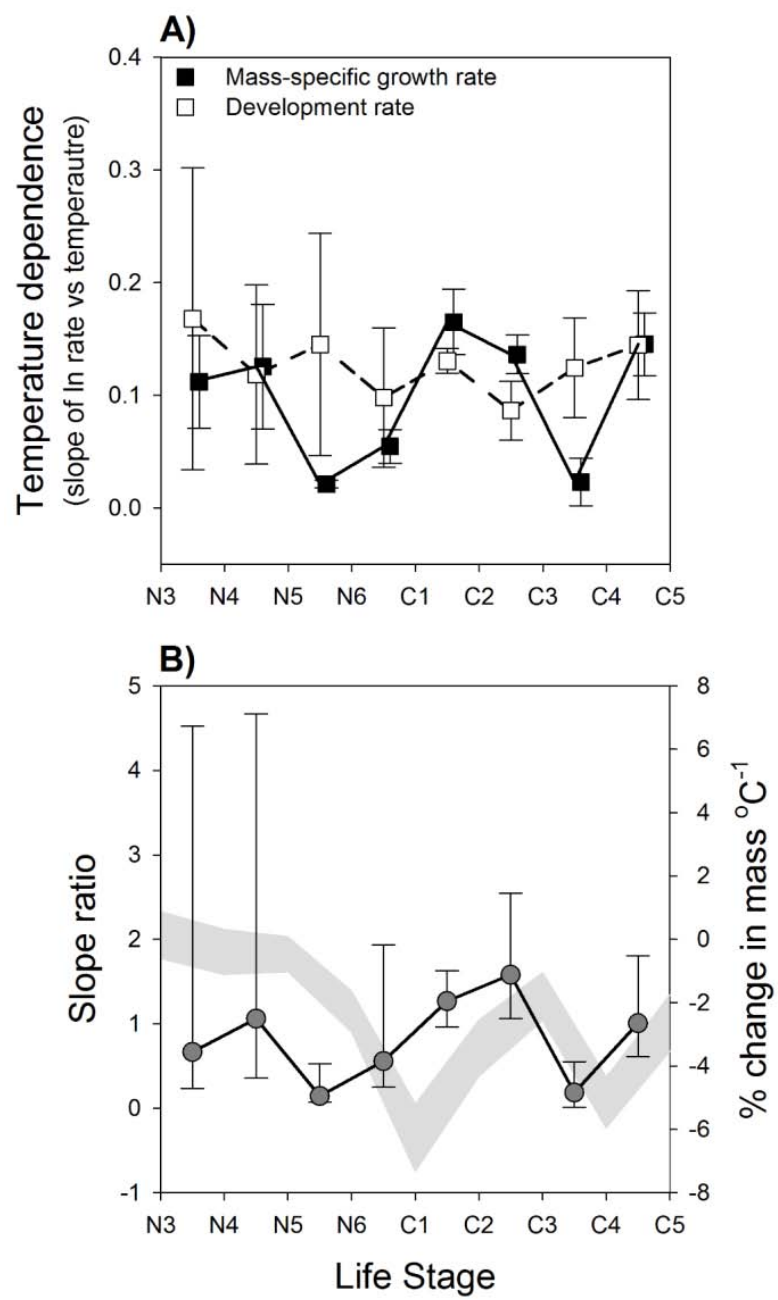

'This article is protected by copyright. All rights reserved.' 
Figure 5. Examples from the literature of stage-specific temperature-size responses (percentage change in mass per ${ }^{\circ} \mathrm{C}$ ) in insects. Data for A. aegypti and C. quinquefasciatus (panels A and B) adapted from Rueda et al. (1990). Data for A. fabae (panel C) adapted from Li and Mills (2004). Data for H. virescens (panel D) adapted from Nadgauda and Pitre (1983). Error bars denote standard error. In each case note the episodic progression of the temperature-size response over ontogeny, indicative of changes in the extent to which growth and development rates are thermally decoupled (see Table 1).
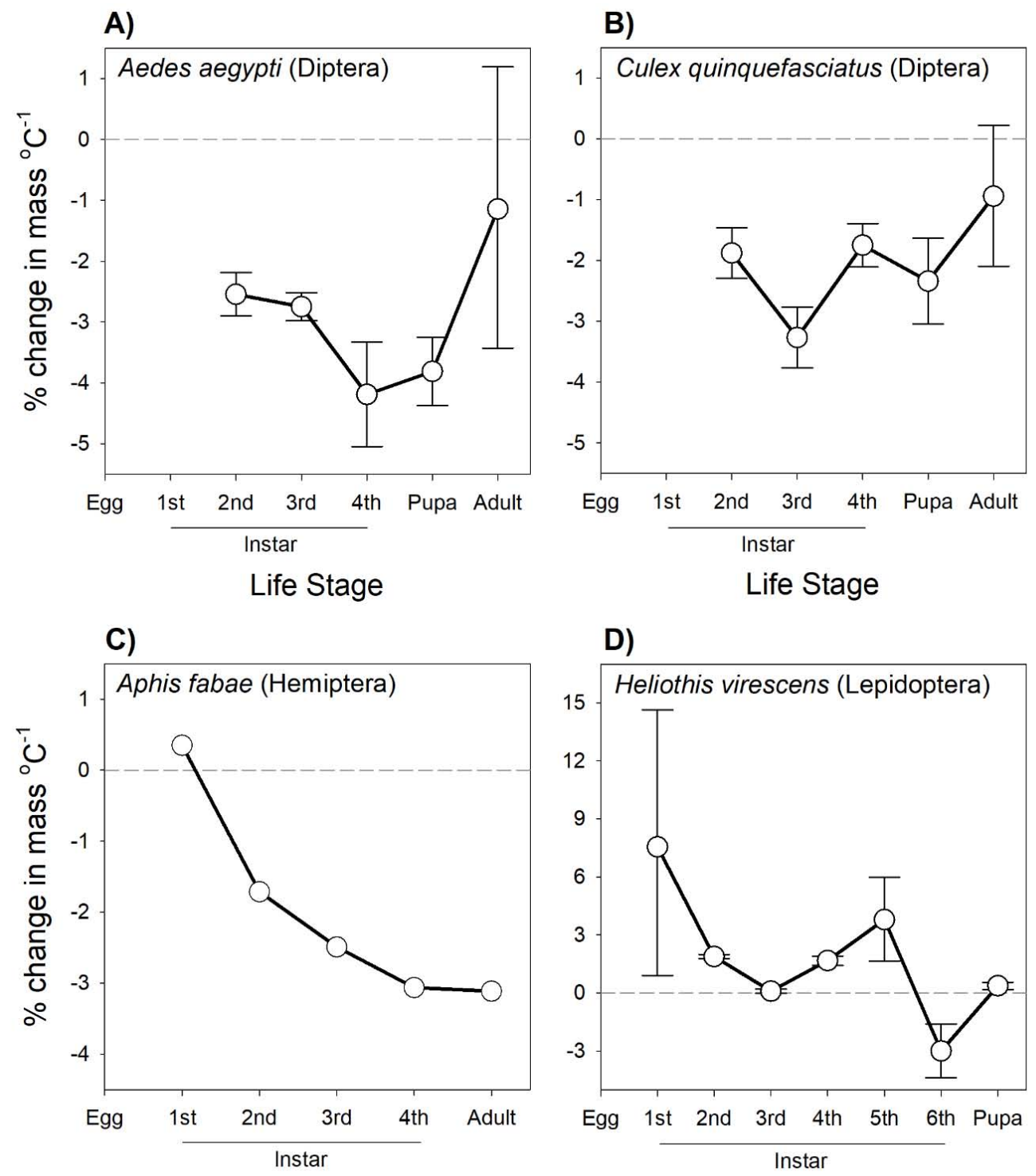

\section{D)}

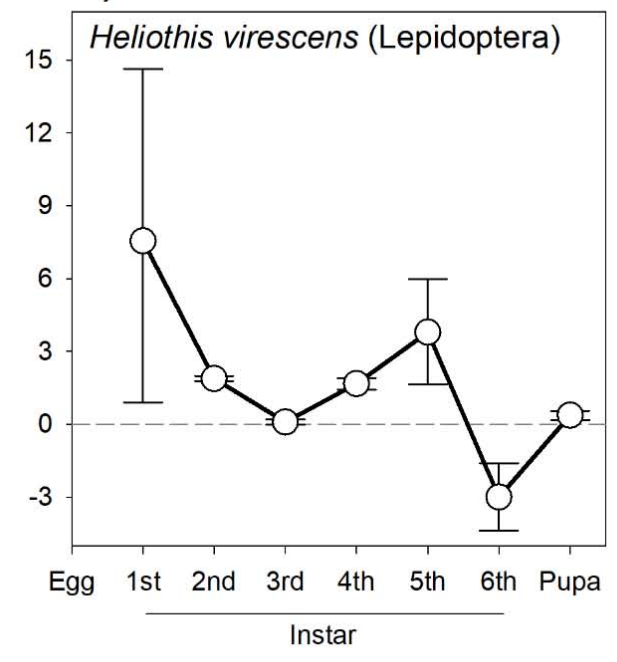

Life Stage 


\section{Table Legends}

Table 1. Examples from the literature of ontogenetic variation in the temperature dependence of growth and development rates in other arthropod species, including insects and crustaceans.

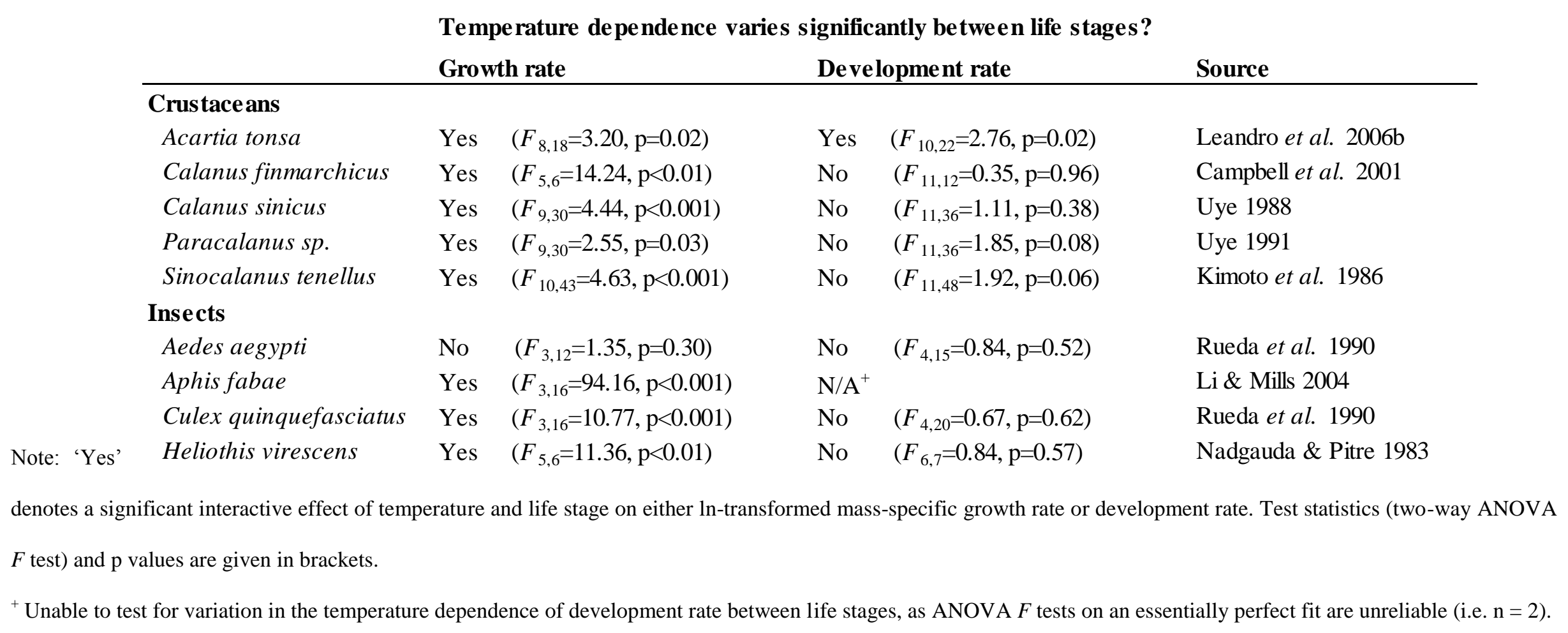

'This article is protected by copyright. All rights reserved.' 